\title{
O PLANEJAMENTO FINANCEIRO E AS MICRO E PEQUENAS EMPRESAS NO BRASIL ${ }^{1}$
}

\author{
PADUA, Kamila Lube ${ }^{2}$
}

\section{Resumo}

A finalidade desse artigo é mostrar a importância do planejamento financeiro para as Micro e Pequenas Empresas sobreviverem. O obstáculo analisado foram os próprios empreendedores, que muitas vezes não tem preparação para administrar os recursos financeiros disponíveis. O estudo permitirá, também, apurar através de dados estatísticos do SEBRAE a situação das Micro e Pequenas Empresas no Brasil.

\section{Palavras-chave: Planejamento Financeiro, Sobrevivência Empresarial, Micro Empresa, Pequena Empresa, MPE.}

\section{Introdução}

É através do controle financeiro que uma empresa se mantém. Por isso, o planejamento financeiro consolida a forma pelo qual os objetivos almejados poderão ser alcançados. Controle e planejamento financeiro são fundamentais para qualquer tipo de empresa. Mas em geral, são as Micro e Pequenas Empresas (MPEs) que carregam uma situação delicada, em consequência do baixo conhecimento de técnicas administrativas por parte dos administradores acumulado ao obstáculo da carência de capital de giro.

A problemática analisada é que, nesse tipo de empresa, o empreendedor, por vezes, não sabe administrar os recursos financeiros disponíveis. Fitzpatrick (1932) foi um dos pioneiros a trabalhar nesse

\footnotetext{
${ }^{1}$ Artigo elaborado a partir da experiência adquirida no estágio obrigatório na empresa Erivelto Fernando Rodrigues-ME para a matéria de Estágio I, do Curso de Administração da UNITINS no período de 08 de março de 2010 a 22 de abril de 2010. Orientador: Omar Raimundo de Paula Teixeira. A empresa é segmentada no ramo de construção civil, especificamente na produção de placas de gesso, e se encontrava com problemas financeiros na época. Após apuração da situação da empresa, foi constatado que o problema era consequência de má administração dos recursos financeiros nos primeiros anos após sua criação.

${ }^{2}$ Graduanda de Administração. Fundação Universidade de Tocantins - UNITINS.
} 
tema, quando comparou dezenove empresas bem sucedidas com outras dezenove empresas falidas entre 1920 e 1929 nos Estados Unidos. No Brasil, o pioneiro foi Kanitz (1976) e seu "Termômetro de Kanitz", que previa a possibilidade de falência de empresas através de uma equação básica.

\section{Planejamento Financeiro}

Sanvicente \& Santos (1983, p. 155) afirmam que

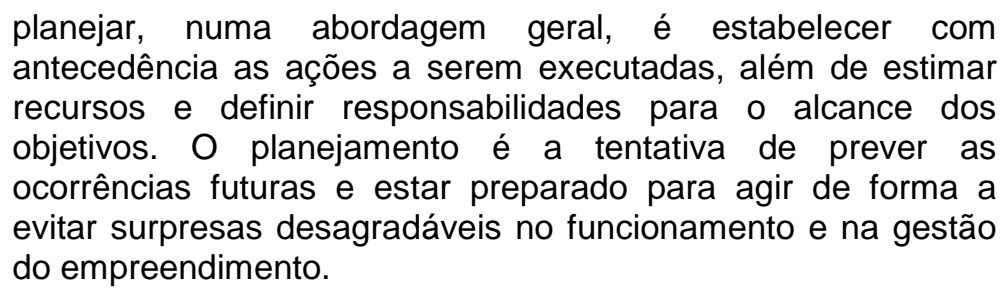

Portanto, o ato de planejar traz a possibilidade de compreender direções e prever situações, evitando problemas futuros e dando tempo ao administrador para buscar soluções.

Ross et al (2002, p. 525) afirmam que:

o planejamento financeiro estabelece o método pela quais as metas financeiras devem ser atingidas. A meta mais frequente adotada pelas empresas é o crescimento.

Neste âmbito, o planejamento financeiro busca consolidar seus alvos almejados através do planejamento e pode conceber um orçamento gerencial, agregando-o aos demais setores que necessitam de controle.

\section{Micro e Pequenas Empresas}

As MPEs (Micro e Pequenas Empresas) surgiram com os primeiros artesãos na Europa Feudal, há mais de 500 anos atrás. Suas primeiras localizações eram nos Burgos, cidades de acentuado comércio. Seus produtos eram variados e, também nessa época, surgiram os primeiros prestadores de serviço: carregadores, transportadores de pessoas, concerto de equipamentos, et cetera. 
Hoje, na economia brasileira, as MPEs conquistaram sua fatia do mercado e muitos benefícios. Segundo dados do SEBRAE (2011, p. 43), as MPEs somam $99 \%$ dos estabelecimentos formais do país. Estima-se que mais de $50 \%$ dessas empresas sejam familiares. Ainda segundo o SEBRAE (2011, p. 45), "o maior motivo de início de uma MPE é a descoberta de uma oportunidade de negócio. [...] O segundo maior motivo é a experiência em outra MPE [...]", o que traz maior possibilidade de sucesso.

No Brasil, é considerado Micro Empresa estabelecimentos que possuam faturamento anual de, no máximo, $R \$ 240$ mil por ano. $A$ Pequena Empresa deve faturar entre $R \$ 240.000,01$ e $R \$ 2,4$ milhões anualmente.

\section{Ferramentas de Controle Financeiro}

São várias as ferramentas que podem ser usadas no processo de gerenciamento de uma empresa. As mais simples destas ferramentas são o fluxo de caixa e o orçamento.

Segundo Campos Filho (1997, p. 109),

entende-se como fluxo de caixa o registo e controle sobre a movimentação do caixa de qualquer empresa, expressando as entradas e saídas de recursos financeiros ocorridos em determinados períodos de tempo.

O fluxo de caixa é uma das principais ferramentas de diagnóstico, pois expõe as receitas e despesas da empresa em ordem cronológica auxiliando o administrador na tomada de decisões evitando, assim, ameaças à empresa, como falta de liquidez ou insolvência, por exemplo.

Segundo Taylor (1971, p. 33),

orçamento é uma ferramenta de gestão que explicita as intenções da empresa em termos financeiros. O orçamento é 
uma ferramenta adotada para o controle de suas finanças, sendo que contemplam duas das funções básicas: 0 planejamento e o controle.

Pode-se dizer que o orçamento é a síntese da estratégia da empresa e delimita metas específicas de produção, distribuição, venda, et cetera. Frequentemente toma a forma de um Orçamento de Caixa ${ }^{3}$, uma Demonstração de Resultados do Exercício (DRE) ${ }^{4}$ e um Balanço Patrimonial ${ }^{5}$. Dentre vantagens obtidas, destacam-se o planejamento futuro, exibição de possíveis problemas ou erros, e fixação de metas referencias para a futura avaliação de desempenho obtido.

Ruschel (2005, p. 01) afirma que

a ausência da gestão de custos contribui para que muitas empresas encerrem suas atividades, sem que seus proprietários possam, sequer, identificar as causas.

Geralmente, é necessário que os usuários dos modelos de planejamento financeiro determinem algumas previsões. Os modelos são diferenciados e complexos, de acordo com o tipo de empresa.

Evidenciando o caso da MPEs, o controle financeiro está intimamente relacionado ao seu porte com pequeno grau de complexidade operacional. É comum nesses casos o sócio ter funções gerenciais e operacionais, possibilitando-o ter alto grau de conhecimento de várias atividades o que o auxiliará na tomada de decisões.

\section{Resultados}

De acordo com a análise, toda empresa precisa de um alicerce seguro para ter um bom início. O planejamento financeiro determina 0

\footnotetext{
${ }^{3}$ Permite a empresa saber suas necessidades financeiras a Curto Prazo.

${ }^{4}$ Evidencia a formação de resultado líquido de capital em um determinado período, através de confronto de receitas, custos e despesas.

${ }_{5}$ Evidencia, quantitativa e qualitativamente, num determinado período, a posição patrimonial e financeira da empresa.
} 
melhor rumo para o desenvolvimento da organização de forma global evitando problemas através de elaboração de recursos alternativos, no caso de possíveis eventualidades.

Já o novo empresário deve compreender as particularidades e etapas da abertura de uma empresa além da área em que pretende trabalhar. Deve conhecer os aspectos legislativos e normativos e buscar sempre a melhoria da empresa. Também precisa ter espírito empreendedor, ser criativo e investigador. Tudo isso é de extrema importância para o sucesso da nova empresa.

\section{Discussão}

As MPEs possuem 99\% (SEBRAE, 2011, p. 43) do mercado brasileiro e, consequentemente, são uma grande fonte de emprego. Porém, a maior parte dessas MPEs não tem sucesso por muito tempo. Segundo o SEBRAE "tomando como referência as empresas brasileiras constituídas em 2006, a taxa de sobrevivência das empresas com até 2 anos de atividade foi de $73,1 \%$ " (2011, p.14).

É frequente a má administração dos recursos financeiros nas MPEs recém-criadas. Os empreendedores não estão 'acostumados' a planejar e isso dificulta a vida e evolução da empresa, principalmente porque, geralmente, as MPEs não possuem grandes reservas de capital, estando despreparadas para os primeiros problemas que irão surgir.

O empresário deve estar atento às ferramentas que utiliza para o planejamento e sempre acompanhar os resultados obtidos. O cenário empreendedor deve ser sua base para cálculos e ajustes nas ferramentas usadas.

\section{Conclusão}

Conclui-se que o planejamento financeiro é um elemento decisivo no funcionamento das MPEs, e que o controle financeiro é o diferencial 
que torna a sobrevivência viável. Toda organização precisa de um planejamento financeiro para estabelecer metas e executar alterações, quando for necessário.

Também é necessário que o administrador possua vocação para a atividade empresarial, saiba liderar, ser persistente e comprometido, tenha criatividade e iniciativa, saiba correr riscos calculados e tenha as habilidades de organizar, planejar, controlar e conduzir a empresa. Com isso somado às ferramentas comuns (fluxo de caixa e orçamento), os administradores podem traçar o futuro das organizações através dos resultados obtidos e, enfim, comparar os resultados com o que foi planejado, chegando a uma conclusão de sucesso ou não.

\section{Referências Bibliográficas}

- CAMPOS FILHO, Ademar. Demonstração dos Fluxos de Caixa: Uma ferramenta indispensável para administrar sua empresa. 2 ${ }^{\text {a }}$ Edição. São Paulo: Atlas, 1997.

- ROSS, Stephen A.; WESTERFIELD, Randolph W.; JAFFE, Jeffrey F. Administração Financeira: Corporate Finance. $2^{2}$ Edição. São Paulo: Atlas, 2002.

- RUSCHEL, Cláudio Fernando. Custos... Estes desconhecidos... Markup Custos e Assessoria, outubro de 2005. Disponível em: http://www.markup.srv.br/artigos det.php?id=1. Acesso em: 14 de novembro de 2012, 13:40.

- SANVICENTE, Antonio Zoratto; SANTOS, Celso da Costa. Orçamento na administração de empresas. $2^{\underline{a}}$ Edição. São Paulo: Atlas, 1983.

- SEBRAE. Anuário do Trabalho na Micro e Pequena Empresa 2010/2011. 4ª Edição. São Paulo: SEBRAE, 2011.

- SEBRAE. Taxa de Sobrevivência das Empresas no Brasil. Editoração Eletrônica. São Paulo: SEBRAE, 2011.

- TAYLOR, Frederick W. Princípios de Administração Científica. $7^{a}$ Edição. São Paulo: Atlas, 1971. 